\title{
COPPER (II)-SELECTIVE MEMBRANE ELECTRODES BASED ON Cu (II)-SCHIFF BASE COMPLEXES AS AN IONOPHORE
}

\author{
Mustafa Taştekin", Filiz Tunalı, Orhan Atakol, Esma Kılıç \\ Department of Chemistry, Faculty of Science, Ankara University, \\ Ankara, Turkey
}

\begin{abstract}
A new PVC membrane electrode for copper (II) ion based on the mixture of mononuclear aqua-[N,N'-bis(salicylidene)-1,3-propane-diaminato|copper (II) (I) and dinuclear dioxane-[N,N'-bis(salicylidene)-1,3-propanediaminato]dicopper (II) dichloride (II) is developed. The electrode exhibits a Nernstian response for copper (II) ion over a wide concentration range, $1.0 \times$ $10^{-1}-3.2 \times 10^{-5} \mathrm{M}$ with a slope of $28.3 \mathrm{mV}$ per decade. It has a relatively fast response time, $20-30 \mathrm{~s}$, and can be used for at least four months without any considerable divergence in potential. The proposed electrode shows a high selectivity against $\mathrm{Ca}$ (II), Co (II), Zn (II), $\mathrm{Ni}$ (II), $\mathrm{Mg}$ (II), $\mathrm{Sr}$ (II), $\mathrm{Ba}$ (II), Cd (II), $\mathrm{Al}$ (III), $\mathrm{Na}$ (I), $\mathrm{Hg}$ (II) and $\mathrm{Mn}$ (II) and can be used in a $\mathrm{pH}$ range 4.5 6.5. Only $\mathrm{Ag}$ (I) ion was observed to have a significant interference. It is successfully used as an indicator electrode in potentiometric titration of copper (II) with EDTA and direct potentiometric determination of copper.
\end{abstract}

Key words: Potentiometry, Copper (II)-selective electrode, Schiff basecopper complexes, PVC membrane, determination of copper, alloys.

\section{INTRODUCTION}

As is known, Schiff bases are reagents, which are becoming increasingly

\footnotetext{
Corresponding author. Tel.: +90-312-2126720/1281;

Fax: +90-312-2232395; E-mail address: tastckin(â)sciencc.ankara.cdu.tr
} 
important in the pharmaceutical, dye and plastic industries as well as for liquid-crystal technology and mechanistic investigations of the drugs used in pharmacology, biochemistry and physiology in addition to their uses in analytical chemistry $/ 1 /$. However, the latest research has revealed that Schiff bases and/or their metal complexes can be employed as ionophores in the construction of many anion or cation-selective electrodes /2-6/.

It is known that copper ion forms stable complexes with Schiff bases 7 , 8/. It was reported that the mononuclear aqua $/ \mathrm{N}, \mathrm{N}^{\prime}$-bis(salicylidene)-1,3propane-diaminato/copper (II) complex could be used as a titrant in the titrimetric determination of copper /9/. There are also several other studies related to the preparation of copper (II)-selective electrodes by the use of other Schiff bases and their complexes /10-14/.

In this study an attempt was made to prepare a $\mathrm{Cu}$ (Il)-selective electrode using Cu (II)-Schiff base complexes in PVC based membranes. For this purpose a mixture of mononuclear aqua [N,N'-bis(salicylidene)-1,3-propanediaminato]copper (II) (I) and dinuclear dioxane [N,N'-bis(salicylidene)-1,3propane-diaminato]dicopper (II) dichloride (II) was used as an ionophore. The structures of Schiff base-copper (II) complexes are given in Fig. 1.

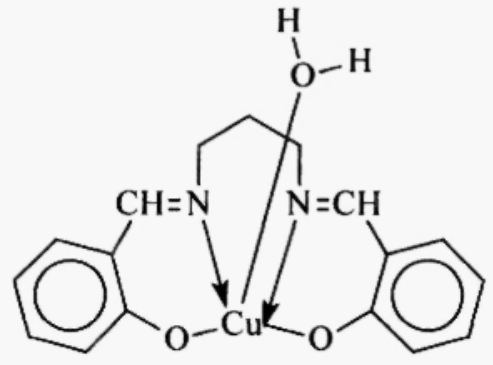

(I)

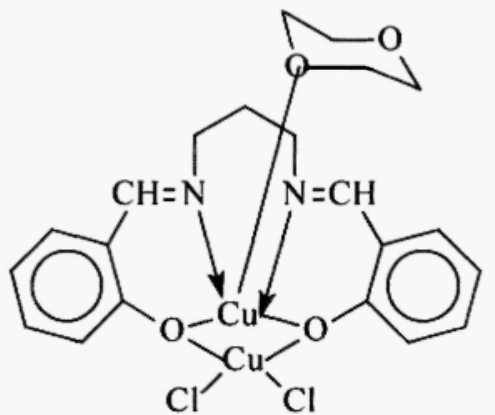

(II)

Fig. 1: The structures of mono and dinuclear $\mathrm{Cu}$ (II)-Schiff base complexes used as ionophore. (I) Aqua [N,N'-bis(salicylidene)-1,3-propanediaminato]copper (II). (II) Dioxane $[\mathrm{N}, \mathrm{N}$ '-bis(salicylidene)-1,3propane-diaminato]dicopper (II) dichloride.

The structure of the mononuclear complex given in Fig. 1 was elucidated with $\mathrm{x}$ - ray crystallography $/ 15 /$. The structure of the dinuclear complex was proposed as depicted in Fig. 1 based upon elemental analysis data and a 
structure given for a similar compound in the literature $/ 16 /$.

In this study the $\mathrm{pH}$ range, selectivity against other ions, response time and lifetime of the $\mathrm{Cu}$ (II)-selective electrode were determined. The practical aspects of using the electrode for the determination of copper in real samples were also investigated.

\section{EXPERIMENTAL}

\subsection{Reagent and solutions}

All chemical substances used were of reagent grade and were used without further purification. The stock solutions of metal ions were $0.1 \mathrm{M}$. Working solutions were obtained by proper dilution of the stock solutions with deionized water.

Mononuclear aqua [N,N'-bis(salicylidene)-1,3-propane-diaminato]copper (II) (I) and dinuclear dioxane [N,N'-bis(salicylidene)-1,3-propanediaminato]dicopper (II) dichloride (II) complexes were synthesized at the Department of Analytical Chemistry, Ankara University by Atakol et al /15/.

High molecular weight poly(vinyl chloride) (PVC), 2nitrophenyloctylether (2-NPOE) and tetrahydrofurane (THF) were obtained from Fluka in selectophore purity. Sodium tetraphenylborate (STPB) was purchased from Aldrich.

Standard reference materials (Messing XV: Cu $63.76 \%, \mathrm{~Pb} 1.90 \%$, Sn $0.08 \%$, Fe $0.14 \%$, Ni 0.14\%, Zn 34.06\%; Messing VII: Cu 84.96\%, Pb $0.15 \%, \mathrm{Sn} 0.02 \%, \mathrm{Fe} 0.01 \%, \mathrm{Ni}$ (spuren), $\mathrm{Zn} 14.86 \%$ ) were obtained from Dr Hoefner's Subztanz Company. Suitable amounts taken from these standard materials were dissolved using nitric acid and diluted to a certain volume.

pHs of test solutions were adjusted to about 5.6 using acetic acid/acetate buffer. The ionic strength of the solution was maintained at $0.25 \mathrm{M}$ potassium nitrate.

The studies were carried out by the use of deionized water obtained from Barnstead Nanopure Infinity Ultra Pure Water System.

\subsection{Preparation of the electrode}

$10.0 \mathrm{~mL}$ of stock solution containing $0.5 \mathrm{mg}$ mononuclear, $0.5 \mathrm{mg}$ dinuclear and $8.0 \mathrm{mg}$ sodium tetraphenylborate (STPB) per $1.0 \mathrm{~mL}$ 
tetrahydrofurane was prepared (solution A). $90.0 \mathrm{mg}$ 2-nitrophenyloctylether and $40.0 \mathrm{mg}$ poly(vinyl chloride) were dissolved in $2.0 \mathrm{~mL}$ of THF (solution B). $1.0 \mathrm{~mL}$ of solution A was added to solution B. The homogenous mixture formed was poured onto a glass disc with a diameter of $2.6 \mathrm{~cm}$ attached to a glass plate and kept at room temperature for $24 \mathrm{~h}$ for the evaporation of tetrahydrofurane. The $0.7 \mathrm{~cm}$ diameter disc of the polymer membrane was cut and fixed to the end of a glass tube with a diameter of $0.5 \mathrm{~cm}$ and a length of $10 \mathrm{~cm}$.

An internal filling solution containing $1.0 \times 10^{-3} \mathrm{M} \mathrm{Cu}\left(\mathrm{NO}_{3}\right)_{2}$ and saturated $\mathrm{KCl}$ was put into this glass tube and a $\mathrm{AgCl}$-coated silver wire was inserted into it. The prepared PVC electrode was conditioned in $1.0 \times 10^{-3} \mathrm{M}$ $\mathrm{Cu}\left(\mathrm{NO}_{3}\right)_{2}$ solution for $12 \mathrm{~h}$. The copper (II) ion-selective electrode obtained was also used as an indicator electrode.

\subsection{Potential measurements}

Using the single-junction $\mathrm{Ag} / \mathrm{AgCl}$ reference and the copper (II)-ion selective electrodes the following electrochemical cells were prepared.

Reference electrode $\mid$ analyte solution $\mid$ membrane $\mid 1.0 \times 10^{-5} \mathrm{M}$ $\mathrm{Cu}\left(\mathrm{NO}_{3}\right)_{2}$ saturated $\mathrm{KCl}|\mathrm{AgCl}| \mathrm{Ag}$.

The potential measurements were made by the use of Jenway 3040 Ion Analyser Model $\mathrm{pH}$ ion meter. The reference electrode was a single-junction $\mathrm{Ag} / \mathrm{AgCl}$ electrode and a filling solution employed for this electrode was that of Orion's with catalogue number 90000l. The $\mathrm{pH}$ measurements were performed with Ingold (10.402.3311) combined glass electrode. The combined glass electrode was kept in water when it was not in use. The experimental solution was stirred with a magnetic stirrer and the potentials were recorded after the equilibrium potentials had been reached.

\section{RESULTS AND DISCUSSION}

\subsection{The determination of the composition of the membrane}

The literature survey showed that the usual range of composition in the preparation of PVC matrix membrane electrodes was 1-7\% ionophore, 28$33 \%$ PVC (internal matrix), 60-69\% plasticizer (solvent) and $0.03-2 \%$ 
lipophilic anion /16/. Therefore, the optimum membrane composition was sought within this composition range.

Using these values, the optimum membrane composition was defined by changing the ratio of Schiff base-copper complex, PVC, plasticizer and lipophilic anion and the membrane compositions used for five electrodes are given in Table 1. As can be seen from the table, the membranes contain only mononuclear or dinuclear $\mathrm{Cu}$ (II) complexes and their $1: 1(\mathrm{~m} / \mathrm{m})$ mixture. Furthermore each membrane includes STPB as lipophilic anion.

Table 1. The compositions of Cu (I1)-sensitive membranes

\begin{tabular}{cccccccc}
\hline $\begin{array}{c}\text { Electrode } \\
\text { No }\end{array}$ & $\begin{array}{c}\text { PVC } \\
(\mathrm{mg})\end{array}$ & $\begin{array}{c}\text { Mononuclear } \\
\text { Cu (II) } \\
\text { complex, mg }\end{array}$ & $\begin{array}{c}\text { Cu (II) } \\
\text { complex, } \\
\text { mg }\end{array}$ & $\begin{array}{c}\text { NPOE, } \\
\mathrm{mg}\end{array}$ & $\begin{array}{c}\text { STPB, } \\
\mathrm{mg}\end{array}$ & $\begin{array}{c}\text { THF, } \\
\mathrm{mL}\end{array}$ & $\begin{array}{c}\text { Slope, } \\
\mathrm{mV} / \mathrm{pCu}\end{array}$ \\
\hline 1 & 50.9 & - & 1.0 & 91.1 & 7.5 & 2.5 & 10.2 \\
2 & 45.0 & 0.375 & 0.375 & 90.0 & 5.0 & 3.4 & 20.1 \\
3 & 40.0 & 0.35 & 0.35 & 100.1 & 4.0 & 3.6 & 24.1 \\
4 & 40.0 & 0.5 & 0.5 & 90.0 & 8.0 & 2.8 & 28.3 \\
5 & 40.1 & 1.0 & - & 90.2 & 8.0 & 2.8 & 23.5 \\
\hline
\end{tabular}

The five electrodes were prepared by the use of membranes listed in Table 1 . The calibration graphs were plotted and the slope and the linear working range of each electrode were determined. The electrode constructed by the use of the membrane 4 showed a near Nernstian response with a slope of $28.3 \mathrm{mV} / \mathrm{pCu}$ over a $\mathrm{Cu}(\mathrm{II})$ concentration range of $1.0 \times 10^{-1}-3.2 \times 10^{-5} \mathrm{M}$.

That the response of electrode 1 against $\mathrm{Cu}$ (II) is weak is attributed to the fact that the dinuclear complex is weak; easily splits into $\mathrm{CuCl}_{2}$ and the mononuclear species in aqueous media; and thereby, we must have obtained a polymer membrane with a homogenous distribution of $\mathrm{Cu}^{2+}$ ions. With such a membrane, reaching a $\mathrm{Cu}$ (II) ion concentration gradient could only be possible through a leaching process of $\mathrm{Cu}$ (II) from the membrane to the solution and this would take a long time

On the other hand, with electrode 5 , all the $\mathrm{Cu}$ (II) ions in the membrane are strongly held by the ligand and the $\mathrm{Cu}$ (II) concentration gradient is expected to be established through diffusion of the $\mathrm{Cu}$ (II) ions from the solution into the membrane; thereby a quicker and more intense potential difference across the faces. 
With a mixture of (I) and (II) (electrode 4), the leaching and diffusion processes would be in action simultaneously, and the setting of a $\mathrm{Cu}$ (II) concentration gradient would take least time, which is the case. Indeed, electrode 4 appears to be virtually of Nernstian behavior.

It is known that the addition of a lipophilic anion to the medium changes the specific features of the electrodes with ionophore membranes $/ 17,18 /$. In our study, the data listed in Table 1 reveal that the sensitivities of the membranes against $\mathrm{Cu}$ (II) ions prepared without the use of sodium tetraphenylborate (STPB) as lipophilic salt is low. The addition of the lipophilic reagent improved the sensitivity of the electrode in accordance with the literature $/ 17 /$.

\subsection{Effect of $\mathbf{p H}$}

The influence of the $\mathrm{pH}$ of the test solution on the potential response of the proposed $\mathrm{Cu}$ (II)-selective electrode (electrode no 4) was tested at $1.0 \times$ $10^{-3} \mathrm{M} \mathrm{Cu}$ (II) concentration by changing the $\mathrm{pH}$ between 2 and 7. As seen from Fig. 2, the response of the electrode remains nearly constant within the intervals of $\mathrm{pH} 2.0-3.5$ and of 4.5-6.5. The calibration curves obtained at $\mathrm{pH}$ 4.3, 5.6 and 6.2 are shown in Figure 3. The slope was $17 \mathrm{mV} / \mathrm{pCu}$ at $\mathrm{pH} 4.3$ and increased to 28.3 and $27.0 \mathrm{mV} / \mathrm{pCu}$ at $\mathrm{pH} 5.6$ and 6.2 respectively. The electrode showed no selectivity against $\mathrm{Cu}$ (II) ions at $\mathrm{pH}$ values less than 3.5. The reason behind this is that in acidic media, the protons are attached to the suitable sites in the complexes, partially destroying the complex structure and competing with the $\mathrm{Cu}$ (II), thereby ions preventing their entrance to the membrane. The decrease in the response of the electrode around $\mathrm{pH} 7$ may be due to the formation of some hydroxyl complexes of $\mathrm{Cu}$ (II) ions in the solution. The $\mathrm{pH}$ range where the complex formation is most favored was 4.5-6.5. It was also reported in the literature that this $\mathrm{pH}$ range is the most suitable range for the formation of (I) [10]. We have chosen the optimum working $\mathrm{pH}$ as 5.6. 


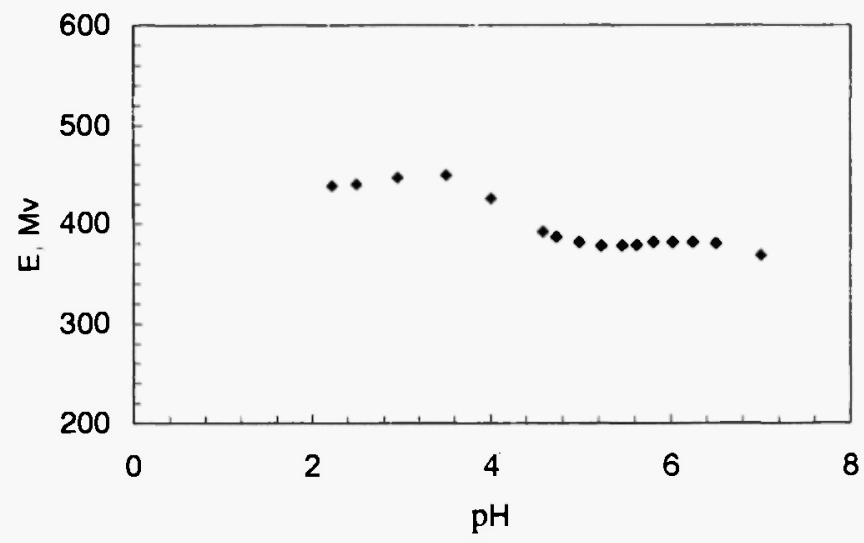

Fig. 2: The effect of $\mathrm{pH}$ on the response of $\mathrm{Cu}$ (II)-selective electrode based on mononuclear aqua [N,N'-bis(salicylidene)-1,3-propanediaminato]copper (II) and dinuclear dioxane [N,N'-bis(salicylidene)-1,3propane-diaminato]dicopper (II) dichloride complexes (electrode 4)

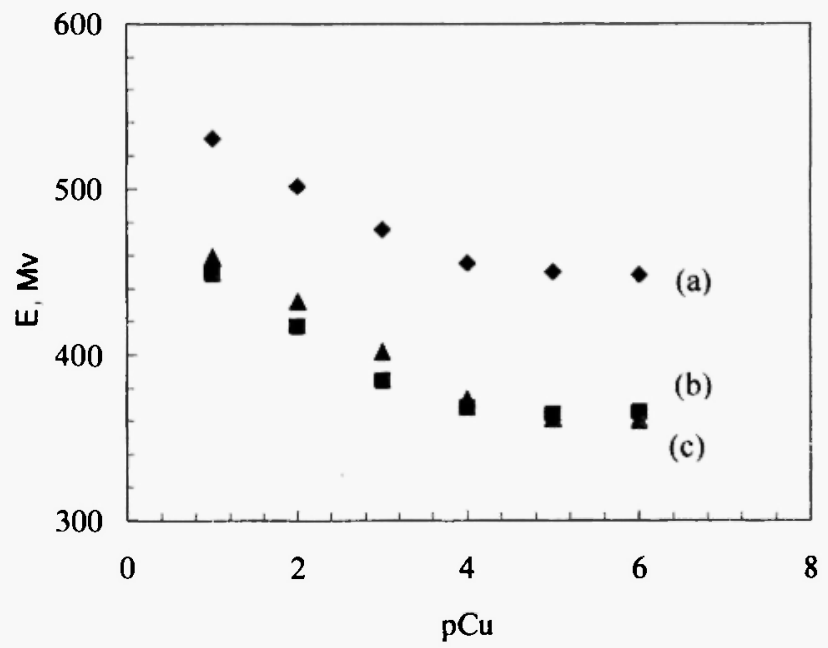

Fig. 3: The calibration curves of the $\mathrm{Cu}$ (II)-selective electrode based on mononuclear aqua-[N,N'-bis(salicylidene)-1,3-propane-diaminato] copper (II) and dinuclear dioxane-[N,N'-bis(salicylidene)-1,3propane-diaminato]dicopper (II) dichloride complexes (electrode 4) at different $\mathrm{pH}$ values: (a) $\mathrm{pH}=4.3$, (b) $\mathrm{pH}=6.2$ and (c) $\mathrm{pH}=5.6$ 


\subsection{Response time and life time of the electrode}

The response time of the electrode depends slightly on the concentration change. The response time was about $30 \mathrm{~s}$ at $\mathrm{Cu}$ (II) concentrations between $10^{-5}$ to $10^{-3} \mathrm{M}$. However it was found to be shorter than $20 \mathrm{~s}$ at concentrations higher than $10^{-3} \mathrm{M}$. This value is comparable to, but is actually shorter than those electrodes reported in the literature, which gave linear response in the same working range $/ 19-22 /$.

The lifetime of the electrode was determined by reading the potentials of a series of $\mathrm{Cu}$ (II) solutions and plotting the calibration curves for a period of 4 months. Fig. 4 illustrates the calibration graphs at different times. Even after 4 months, the slope of the electrode was observed to show no significant change. This shows that the lifetime of the electrode prepared by the use of (I) and (II) complexes was longer than 4 months. This is a longer lifetime than those reported in the literature for similar electrodes $/ 10,22 /$.

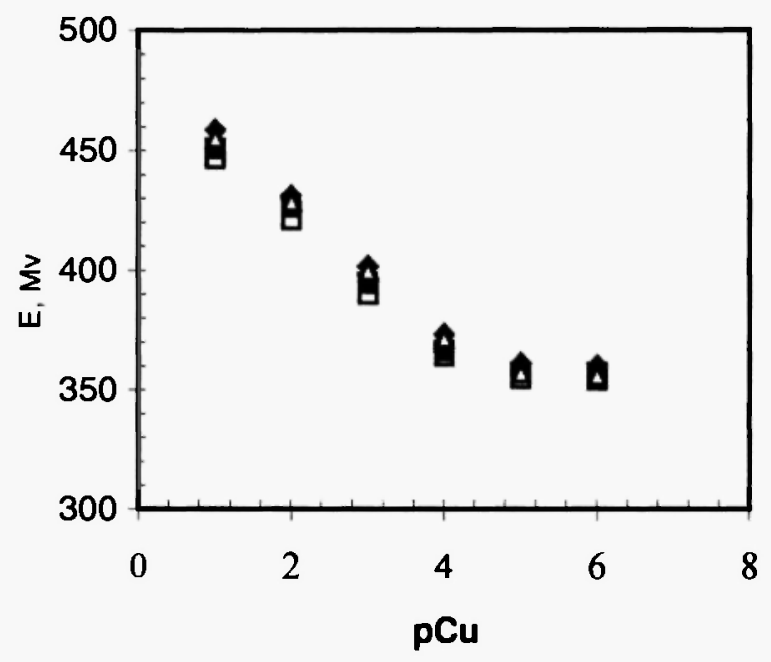

Fig. 4: The calibration curves of $\mathrm{Cu}$ (Il)-selective electrodes plotted at different times: (a) 5 days (b) 30 days (c) 60 days and (d) 120 days

\subsection{The selectivity of the electrode}

The selectivity behavior is obviously one of the most important characteristics of an ion-selective electrode, as it often determines whether a 
reliable measurement in the target sample is possible $[23,24]$. In order to assess the selectivity of the proposed $\mathrm{Cu}$ (II)-selective electrode over other cations such as $\mathrm{Ca}$ (II), $\mathrm{Co}$ (II), $\mathrm{Zn}$ (II), $\mathrm{Ni}$ (II), $\mathrm{Mg}$ (II), $\mathrm{Sr}$ (II), $\mathrm{Ba}$ (II), Cd (II), $\mathrm{Al}$ (III), $\mathrm{Na}$ (I), $\mathrm{Hg}$ (II), $\mathrm{Mn}$ (II) and $\mathrm{Ag}(\mathrm{I})$, the mixed interference method was employed $[25,26]$ and the values of the selectivity coefficients are given in Table 2. As can be seen from the table the interference effect of $\mathrm{Ag}$ (I) ion was annoyingly high. This can be attributed to the fact that $\mathrm{Ag}$ (I) ions combine with the chloride ions in dinuclear $\mathrm{Cu}$ (II) complexes and clog the pores so as to obstruct the back and forth movement of $\mathrm{Cu}$ (II) ions. The interfering effects of other ions are ignorable.

\section{Table 2}

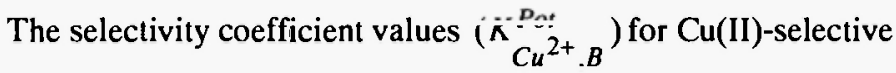
electrode as calculated by mixed interference method

\begin{tabular}{cc}
\hline Interfering ion $(\mathrm{B})$ & Selectivity coefficient values* \\
\hline $\mathrm{Ca}^{2+}$ & $1.8 \times 10^{-2} \pm 3.0 \times 10^{-3}$ \\
$\mathrm{Co}^{2+}$ & $7.1 \times 10^{-2} \pm 3.0 \times 10^{-3}$ \\
$\mathrm{Zn}^{2+}$ & $2.2 \times 10^{-2} \pm 7.4 \times 10^{-3}$ \\
$\mathrm{Ni}^{2+}$ & $7.6 \times 10^{-2} \pm 1.2 \times 10^{-3}$ \\
$\mathrm{Mg}^{2+}$ & $5.5 \times 10^{-2} \pm 2.2 \times 10^{-3}$ \\
$\mathrm{Sr}^{2+}$ & $5.6 \times 10^{-2} \pm 1.0 \times 10^{-3}$ \\
$\mathrm{~Pb}^{2+}$ & $5.2 \times 10^{-2} \pm 1.0 \times 10^{-3}$ \\
$\mathrm{Ba}^{2+}$ & $6.1 \times 10^{-2} \pm 1.0 \times 10^{-3}$ \\
$\mathrm{Cd}^{2+}$ & $6.1 \times 10^{-2} \pm 1.0 \times 10^{-3}$ \\
$\mathrm{Al}^{3+}$ & $7.7 \times 10^{-2} \pm 2.5 \times 10^{-3}$ \\
$\mathrm{Na}^{+}$ & $7.5 \times 10^{-2} \pm 4.0 \times 10^{-3}$ \\
$\mathrm{Hg}^{2+}$ & $3.7 \times 10^{-2} \pm 5.0 \times 10^{-3}$ \\
$\mathrm{Mn}^{2+}$ & $6.6 \times 10^{-2} \pm 7.0 \times 10^{-3}$ \\
$\mathrm{Ag}^{+}$ & $3.2 \pm 0.02$ \\
\hline
\end{tabular}

* at $95 \%$ confidence level $(\mathrm{N}=3)$

\subsection{The analytical applications of the electrode}

Standard Cu (II) solutions were titrated with standard EDTA solution in order to determine whether the proposed electrode could be used as an indicator electrode in the titration of $\mathrm{Cu}$ (II) ions. An example of a titration 
curve thus obtained is given in Fig. 5. As it is seen, the amount of copper (II) ions in solution can be accurately determined with this electrode.

Whether the electrode prepared could actually be employed in real samples was also examined. Copper in various standard reference materials were titrated with EDTA by using the proposed electrode. The results obtained from two reference materials studied are given in Table 3. From the data given in Table 3, the following result from the determination of these standard reference materials with the proposed electrode at $95 \%$ confidence level have been obtained: $85.58 \pm 0.92 \%$ for Messing VII and $63.26 \pm 0.57 \%$ for Messing XV. The copper percentages on the labels of the above mentioned standard reference materials were $84.96 \%$ and $63.76 \%$, respectively. The results obtained with the proposed electrode method show that the difference between the average copper percentage for each standard sample and the copper percentage on the labels, which is at $95 \%$ confidence level and with 5 degree of freedom, is smaller than $t . s / \sqrt{\mathrm{N}}$ values. Therefore, it can be said that the proposed electrode is used for determinations of copper in alloys since the label percentage interval calculated for the average value.

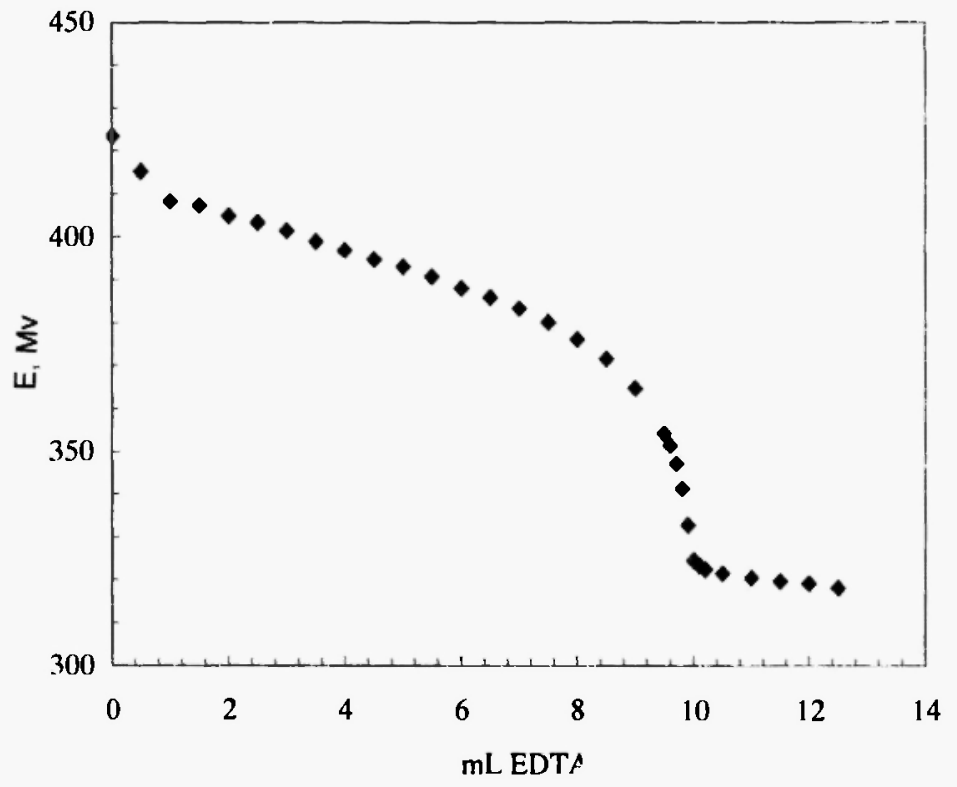

Fig. 5: The potentiometric titration curve of Cu (II) with $0.0200 \mathrm{M}$ EDTA by the use of the proposed $\mathrm{Cu}$ (II)-selective electrode. 


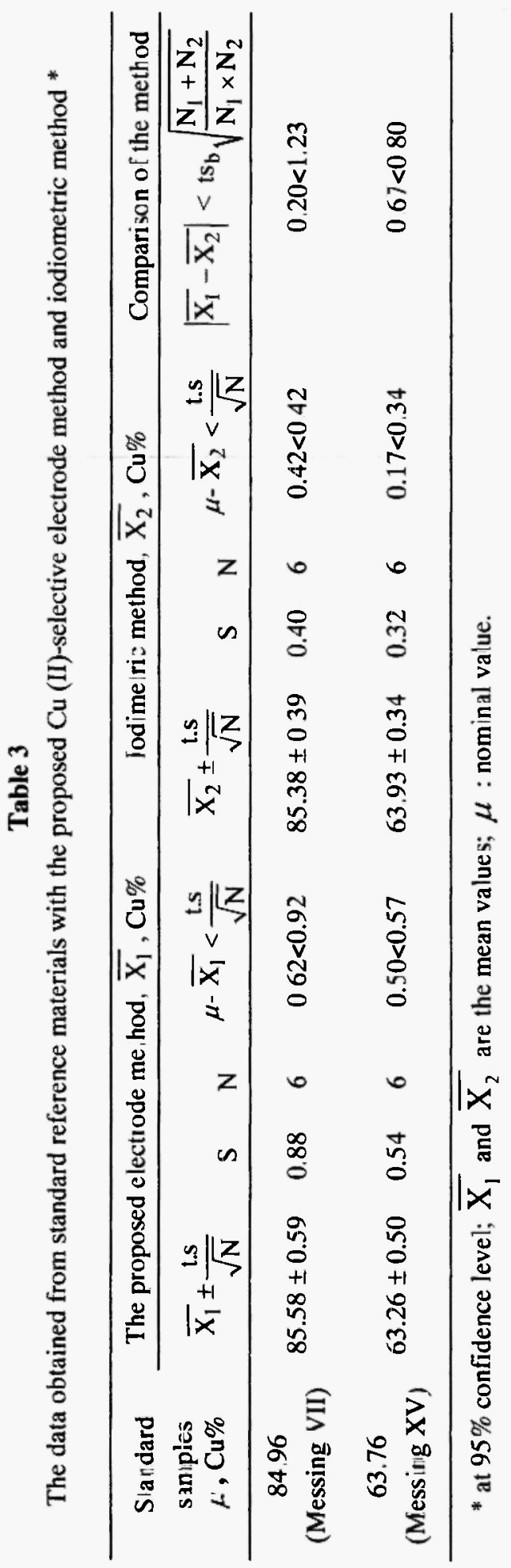


Standard reference materials were also titrated iodometrically using the same conditions and the results are also given in Table 3. As can be seen from the data given in the table, there is no significant difference between the data obtained with these two different methods at a confidence level of $95 \%$.

\section{CONCLUSION}

A $1: 1(\mathrm{~m} / \mathrm{m})$ mixture of mononuclear aqua [N,N'-bis(salicylidene)-1,3propane-diaminato]copper (II) (I) and dinuclear dioxane [N,N'bis(salicylidene)-1,3-propane-diaminato]dicopper (II) dichloride (II) complexes could be used as an ionophore for the construction a of $\mathrm{Cu}$ (II)selective electrode. The electrode is fairly selective against many metal ions. The working $\mathrm{pH}$ range is 4.5-6.5. It was observed that the electrode gave a linear response with a slope of $28.3 \mathrm{mV} / \mathrm{pCu}$ in a concentration range of 1.0 $\times 10^{-1}-3.2 \times 10^{-5} \mathrm{M}$.

The equilibrium time of the electrode to reach a stable potential was relatively short and it was observed that the electrode gave reproducible responses for four months with at least 15 measures per day without any appreciable change in its linearity and slope.

The proposed electrode may be a good alternative to many $\mathrm{Cu}$ (II)selective electrodes reported in literature especially to those solid-state electrodes. The electrode can also be employed as an indicator electrode in the titration of copper with EDTA.

\section{REFERENCES}

1. B. Dash, P. K. Mahapotra, D. Panda and J. M. Pattnaik, Indian J. Chem. Soc. 61 (1984) 1061.

2. J. Lui, Y. Masuda and E. Sekido, Analyst. 115 (1990) 1089.

3. R. Yuan, Y. Q. Chain, D. Lui, D. Gao, J. Z. Li and R.Q.Yu, Anal. Chem. 65 (1993) 2572.

4. S. Ozawa, P. C. Hauser, K. Seiler, S. S. Tan, W. E. Morf and W. Simon, Anal. Chem. 63 (1991) 640.

5. N. Aslan, A. Kenar, O. Atakol and E. Kılıç, Anal. Sci. 17 (2001) 1269.

6. Ö. Başgut, Z. Durmuş, O. Atakol and E. Kılıç, Talanta 57 (2002) 813 
7. O. Atakol, S. Durmuş, C. Arıcı, I. Svoboda and H. Fuess, Main Group Met. Chem. 23 (2000) 791

8. O. Atakol, C. Arıcı, M. N. Tahir, A. Kenar and D. Ülkü, Acta Cryst. C55 (1999) 1416

9. E. Kormalı and E. Kılıç, Talanta 58 (2002) 793

10. N. Alizadeh, S. Ershad, H. Naeimi, H. Sharghi, andM. Shamsipur, Fresenius J. Anal. Chem. 365 (1999) 511.

11. T. Poursaberi, L. Hajiagha-Babaei, M. Yousefi, S. Rouhani, M. Shamsipur, M. Kargar-Razi, A. Moghimi, H. Aghabozorg and M.R. Ganjali, Electroanalysis 13. No. 18 (2001), 1513-1517.

12. S. Sadeghi, M. Eslahi, M.A. Naseri, H. Sharghi and A. Shameli, Electroanalysis 15. No. 15-16 (2003), 1327-1333.

13. P.C. Pandey, Copper (II) ion sensor based on electropolymerized undoped-polyindole modified electrode, Sensors and Actuators B 54(1999), 210-214

14. Z. Y Sun, R. Yuan, Y. Q. Chai, L. Xu, X. X. Gan and W.J. Xu, Anal. Bioanal Chem. 378(2)(2003): 490-4.

15. C. Arıcı, F. Ercan, O. Atakol and O. Cakırer, Acta Cryst. C55 (1999) 1654

16. R. J. Butcher and E. Sinn, Inorg. Chem. 15 (1976) 1604

17. Y. A. Zolotov, Macrocyclic Compounds in Analytical Chemistry 1997, John Wiley and Sons.

18. E. Bakker, A. Xu and E. Pertsch, Anal. Chim. Acta 295 (1994) 253.

19. S. K. Srivastava, N. Pal, R. P. Singh and S. Agarwal, Indian J. Chem. 22A (1983) 1033

20. C. Sun, Y. Sun, Xi Zhang, H. Xu and J. Shen, Anal. Chim. Acta 312 (1995) 207

21. X. Lu, X. Yang and Z. Chen, Electroanalysis 16 (1997) 1278

22. A. K. Jain, P. Singh and L. P. Singh, Indian J. Chem. 33A (1994) 272

23. E. Bakker, P. Bühlmann and E. Pretsch, Chem. Rev. 97 (1997) 3083

24. E. Bakker, Electroanalysis 9 (1997) 7

25. E. Pungor, K. Toth and P. Hrabeczy, Pure Appl. Chem. 51 (1979) 1913.

26. K. Srinivasan and G. A. Rechnitz, Anal. Chem. 41 (1969) 1203. 
